\title{
Darum sollten Sie sich schon jetzt die nächste Ausgabe der Fortbildungsreihe der AG Pädiatrische Radiologie vormerken
}

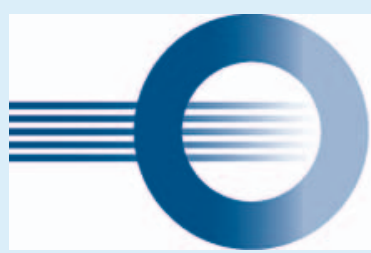

\section{AG Pädiatrische Radiologie}

$$
\text { in der Deutschen Röntgengesellschaft }
$$

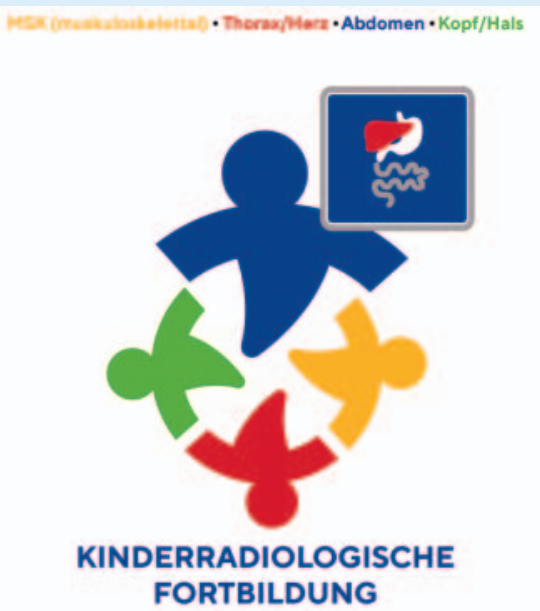

Die Fortbildungsreihe der AG Pädiatrische Radiologie in der Deutschen Röntgengesellschaft bietet einen standardisierten praxistauglichen Überblick über alle wichtigen Themen der Kinderradiologie. Im Rahmen der Reihe werden vier Fortbildungsschwerpunkte für Ärztinnen und Ärzte in Weiterbildung zur Radiologie beziehungsweise Kinderradiologie, für radiologische Fachärztinnen sowie Fachärzte und Kinderradiologinnen beziehungsweise -radiologen angeboten: Kopf/Hals, Muskuloskelettales System, Herz/Thorax und Abdomen. Prof. Dr. Diane Renz (Leiterin des Arbeitsbereichs Kinderradiologie, Institut für Diagnostische und Interventionelle Radiologie, Medizinische Hochschule Hannover) und Dr. Jürgen Weidemann (Chefarzt Kinderradiologie, Kinder- und Jugendkrankenhaus Auf der Bult, Hannover) haben die große Ehre, Sie für die kinderradiologische Fortbildung mit dem Thema Abdomen und Urogenitaltrakt am 11./12.03.2022 im Courtyard-Hotel am Maschsee in Hannover einladen zu dürfen.

Was? Kinderradiologische Fortbildung 2022 - Modul Abdomen

Wo? Courtyard by Marriott Hotel Maschsee Hannover

Wann? 11./12. März 2022

Weitere (Anmelde-)Informationen erhalten Sie über den DRG-Veranstaltungskalender: www.drg.de > Veranstaltungskalender 